\title{
Renew bamboo culture --- Feasibility analysis of bamboo structure in the construction of new countryside
}

\author{
Yuan Xinping ${ }^{1, a}$, Ji Chenhao ${ }^{2, b, *}$
}

${ }^{1}$ Wuhan University of Science and Technology, School of Art \& Design, Hongshan, Wuhan, China

${ }^{2}$ Wuhan University of Science and Technology, School of Art \& Design, Hongshan, Wuhan, China

a823014201@qq.com, b534136845@qq.com

${ }^{*}$ Corresponding author

Keywords: New rural, Original bamboo construction, Feasibility

Abstract. Bamboo is a traditional building material, the application of bamboo construction and its manifestation of form and space is a return to the nature of architecture. China is rich in bamboo resources, and the use of renewable bamboo resources can maximize the realization of the sustainable development of new rural construction. This paper will explore the bamboo construction in depth, research, analyze and extend the discussion of bamboo culture, and finally find a reasonable bamboo construction program, so as to take the bamboo construction program that effectively solve the new rural construction and combine with green technology, and improve the living environment of new rural people greatly.

\section{竹文化的延续——原竹建构在新农村建设中的可行性探析}

\author{
袁心平 $1, a$, 季晨昊 $2, b$, \\ 1 武汉科技大学艺术与设计学院, 洪山区, 武汉, 湖北, 中国 \\ 2 武汉科技大学艺术与设计学院, 洪山区, 武汉, 湖北, 中国 \\ a823014201@qq.com, b534136845@qq.com
}

关键词:新农村; 原竹建构; 可行性

*通讯作者

摘 要: 竹材作为一种传统的建筑材料, 竹建构的应用及其表现出的形式和空间是一种对建筑 本质的回归。我国竹木资源丰富, 利用可再生竹木资源来最大化地实现新农村建设的 可持续发展。本文将竹建构问题深入探索、研究, 分析并延伸讨论竹文化, 最终找到 合理的竹建构方案, 从而采取有效解决新农村建设与绿色科技的相结合的竹建构方案, 并对对新农村人民的生活环境产生显著的改善。

\section{一、现状分析}

1. 国内外现状

1.1 国外竹构建筑的发展及应用现状

与国内竹材运用的现状相比, 国外一些建筑师的设计作品显得更加深入而具有创新性, 他们通过不断探索竹材的材料特性与建构逻辑, 设计出品质优良的作品, 让众人对竹建筑有 了前卫的认识, 这对竹材运用的前景有更重要的促进作用。美国、德国、日本等国家的学者, 都为竹材的推广进行了各种具有创新性与前瞻性的研究实践, 有他们设计的竹构建筑与艺术 装置作品为世人带来了不同的感观体验，同时展示了竹构所具有的丰富多彩的可能性。

国际竹建筑双年展, 以作文命题方式邀请来自世界不同国家的著名设计师参与建筑营造。 双年展充分尊重原住民习俗、历史、生态, 以国际化的视野, 细致梳理乡村的集体记忆, 并 以 “竹” 为载体, 将文化融入建筑设计中。

“他山之石, 可以攻玉”，学习研究与归纳总结国外的优秀建筑师、艺术家以及他们的 作品, 将成为国内竹构发展的基础工作中重要的组成部分, 这也将是改变国内竹材运用滞后 
以及大量使用竹建构技术的有效手段之一。

1.2 国内竹构建筑的发展及应用现状

目前, 国内竹建构技术的应用较少, 竹构建筑发展速度缓慢, 少有优秀竹构建筑作品由 中国建筑师设计。冯纪忠先生设计的上海方塔园中的 “何陃轩” , 如此优秀的竹构建筑在国 内极为罕见。一些主题特色酒店、度假景区、公园小品等临时性或品质需求较低的建筑中开 始大量使用竹材, 当然运用的方式也相对简单, 大多还是以竹材代替木材的基本做法, 竹材 众多的优良的特性在这样的处理方法中并没有得到很好表现。宏观来看, 国内少有优秀的竹 构建筑问世。

在这种竹材运用相对落后的总体情况下, 国内仍有一部分学者在此领域进行了深入的研 究。湖南大学的肖岩教授, 从结构工程师的视角对竹材的材料特征以及力学性质进行深入研 究。2007 年 12 月, 世界上首座能够通行车辆的全竹结构桥梁在湖南未阳市建成通车, 这座 全竹结构的桥梁实际承载能力约 $90 \mathrm{t}$, 跨度达到 $10 \mathrm{~m}^{\mathbf{I} 1 \mathbf{l}}$ 。这是。肖岩教授领导的团队还设计 并实施了一批抗震能力达到八级以上的竹结构的住宅楼, 这也开创了中国建筑领域的先例。

肖岩教授的研究的工作中心多集中在材料与力学还有工程技术领域, 对建筑设计的形式、 空间、建构等问题的研究相对较少。肖岩教授的开创性工作在国内只能算是一枝独秀, 在国 内的建筑领域, 竹构建筑的理论和实践虽然日益得到重视, 但总体的发展水平仍处于相对落 后的状态。

于 2000 年 7 月成立的国际竹藤中心，是国家林业局建立的下属非营利性科学事业单位。 国际竹藤中心在 2004 年与中国林业科学研究院合作设计, 通过使用竹材料, 建成云南省屏边 小学, 整个小学的墙板、屋架、屋面均采用了竹集成板和竹胶合板搭建而成。广州省南昆山 十字水度假区的建筑大量运用了竹建构技术, 其中最具代表性的建筑竹桥, 桥拱长约 25 米, 每平方米内可承重 350 公斤, 竹桥通体圆润呈金黄色, 材料全部采集南昆山当地的毛竹进行 建造。【21

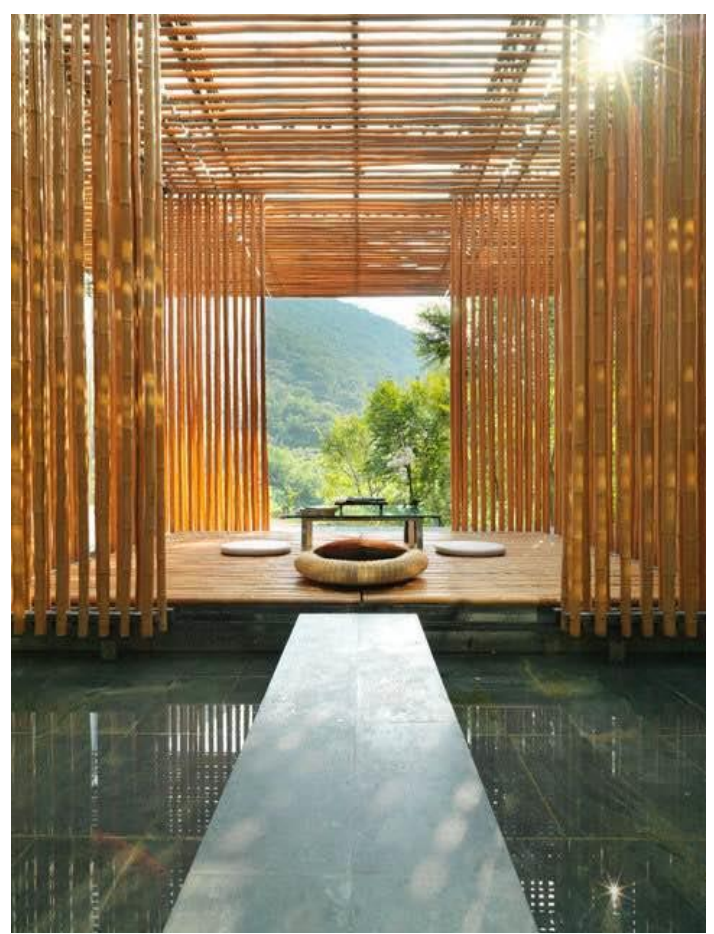

图 1



图 2

\section{二、竹建构在新农村建设中的实践意义 \\ 1 . 竹建构运用于新农村建设中的文化意义}

图 1、图 2 长城脚下公社竹屋, 涱研吾 
竹一一不惧严寒酷暑, 坚韧挺拔, 彰显气节。中国文化中, 竹是 君子的化身。文人墨客把竹子的挺直、常青等特征作为人格化的高雅、 虚心、等精神文化的象征, 我国清代的郑板桥以画竹天下闻名。

古往今来，众多文人雅士常借竹、菊、梅、兰作为自己品德的鉴 戒, 或者来表现内心的清高脱俗。 ${ }^{\mathbf{1}}{ }^{31}$ 因此, 不论是将竹材运用于新农 村建筑或是其他竹制产品, 都暗含了将竹的精神内涵具体化的象征意 义, 或暗喻竹的高洁, 或拟作竹的坚韧品格, 或营造静篮典雅的气氛 环境, 它们都可作为中国文化中的重要组成部分，在新农村建筑中独 特体现。

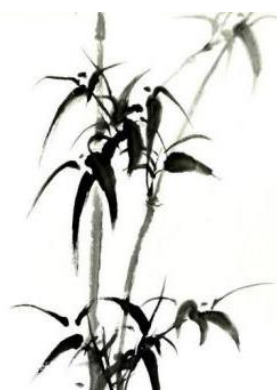

图 3 竹的水墨画表现

除去竹材在中国被赋予的特殊寓意外，这种自古代已有的自然材料在新农村建筑的文化 意义主要体现在其运用的传统, 即材料在地域文化中的传承意义。竹材运用于屋舍的建造由 来已久, 因此, 在竹屋建造历史悠久的地区, 竹材建造是新农村传统住居文化重要的组成部 分。而在现代社会的大量建造过程中, 竹材渐渐被砌块、混凝土等适合快速建造的工业材料 所取代, 传统竹材的建造诗意敌不过日益增长的建设需求。然而, 只需稍加分析便知, 随着 竹建构技术、竹材加工的日趋成熟, 竹材的综合效益是远高于砌块和混凝土的。近年来, 越 来越多的建筑设计师开始关注竹材, 建筑作品中对竹材运用的不断尝试带来了新颖而独特的 视觉感受和空间体验。与此同时, 那些一直专注于竹材在新农村普通住屋营造中如何应用的 建筑师, 用竹质朴的建筑语言, 表达设计师内心对传统的尊重、延续和创新的态度, 传达使 用者对新农村营造工艺、新农村地域文化的理解和认同。

\section{2. 竹材的历史源流}

竹材是一种自然生长的纯天然材料, 在很早以前就应用于建造人们的屋舍以及生活的各 个方面。在其后的传统建造中，竹材的运用方式大致向两种形式分流:

一是, 将竹材为主要建筑材料进行建造的传统竹构建筑。

二是，竹材与其他传统建筑材料合作建造的建筑体系。

当然, 除了在建筑结构体系中的运用, 竹材还被广泛用于室内陈设以及人们日常生活工 具的制作，甚至在造园活动中用作篱笆、栏栅以及竹亭的建造。

原住民是竹建筑最富创造性的建造者。为了避免地面湿气以及洪水的影响, 原始棚屋被 抬高架起。逐渐演变为具有浓郁地域特色的传统竹屋。

优良的力学特性和材料本身的经济性使得竹屋成为热带国家的住民建造住屋的首选。也 正是由于低成本建造的关系, 这一建筑形式在今天仍广泛存在于亚洲、非洲以及美洲的乡村 甚至城市中, 在竹构建筑发展的漫长岁月中, 许多地区慢慢形成了别具一格的建造传统, 如 印度尼西亚(简称印尼)、中国云南、越南、南美厄瓜多尔、哥伦比亚、委内瑞拉, 等等, 竹 构建筑甚至已经成为当地重要的文化象征。

中国传统的傣族竹楼, 是最为经典的全竹建造民居, 是傣族人民因地制宜创造的、形式 具有特色的干阑式住屋。另外, 西南少数民族如布朗族和拉祜族的传统民居也都采用竹楼的 形式。

现代技术的发展以及人们审美水平的变化使得竹材在建筑形态空间以及室内陈设诸多方 面的应用都有了较长足的发展，在新农村建设中正在逐步引入竹建构技术。

\section{3. 竹建构运用于新农村建设中的生态意义}

竹建构具有很好的环境友好性。新农村建筑工程施工过程中需要消耗大量能源, 大量的 新农村建设必然对建筑材料环保性能有较高要求。在环境污染和能源利用方面, 竹材对环境 的影响较之现代建筑建造的主要原料——钢材和水泥要小, 是一种极具环境和生态效益的材 料。

竹材料低技术低成本解决方案对于新农村来说具有很好的推广性。目前竹加工工艺发展 速度快, 竹建构技术有一定的发展基础, 用竹子制成的建筑结构可以组成非常具有想象力的 建筑造型。 
我国木材主要依赖进口，某些国家所提倡的生态环保的木建筑，在中国人均木材储量不 足、木材价格高昂的现实国情下显然不能广泛推行到新农村建设中。我国竹材储量位居世界 第一, 竹资源丰富且, 竹材料特性优良, 是木材最理想的替代品。在我国建材使用现状下, 对于我国当下以及未来大规模新农村建设, 加强 对竹材的开发利用有着显著的生态意义。

\section{三、竹建构在新农村建设中的应用与实践}

\section{1. 竹建构在新农村建设中的应用与实践}

现代技术的发展以及人们审美水平的变化 使得竹材在建筑形态空间以及室内陈设诸多方 面的应用都有了较为长足的发展。因竹材所具有 的优良力学性能、视觉效果和生态环保的材料特 性, 建筑师开始将竹材作为新农村建筑材料加以 使用。另外, 设计者对竹材与新农村地方特色相 结合的创造性构思为建筑带来了更为丰富的视 觉以及空间体验越南建筑师武重义利用竹子作 为原材料, 将越南传统的编制技术融合建筑, 做

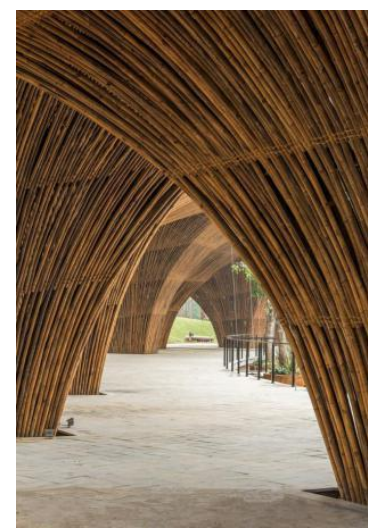

图 4

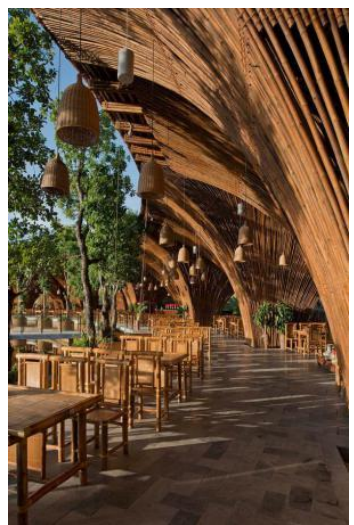

图 5

图 4、图 5 作品 Naman Conference Hal1 武重义 了很多设计实践, 这些作品都是将低成本的当地 材料和传统工艺的当代美学和现代方法进行整合, 形成了一套可持续的建筑设计体系。（见 图 4, 图 5)

在距离浙江省杭州市近 $100 \mathrm{~km}$ 的临安市太阳镇双庙村的太阳公社, 公社周边为丘陵地貌, 山上杂树丛生, 拥有大片竹林, 竹材资源十分丰富。若在新农村建设中大量使用普通砖等普 通建筑材料, 其购置材料和工具的成本和代价巨大。同时山上杂树居多, 难以砍伐作为建材 使用, 而竹材最容易获取和加工。当地的毛竹直径大, 质量好, 适宜用于当地新农村建设, 而且竹子独有中空结构、质轻高强、物理性能好、便于搭建、经济高效, 可再生、可降解、 不污染等优越的材料特性, 能够满足兴新农村经济、高质量而且生态的建造需求。太阳公社 中的很多村民以竹匠作为副业, 熟悉竹编、竹建构等技术的运用。故在太阳公社的新农村建 设中, 设计者使用山上的竹材, 运用了一定的竹建构技术, 同时雇用村里的竹木工匠来完成 新农村建造，这样的建造方式是最为经济合算的。

然而在当下的新农村建设中，竹建构所有的自然、乡村和建筑紧密关联的文化内涵，并没 有得到村民们广泛的理解和重视, 在新农村建设期间, 村民们依旧不忘强调钢筋混泥土等普 通建材的坚固和耐久性。从可持续的角度来看, 将竹材这种低碳的自然材料引新农村建设, 不断改进和运用竹建构技术, 探索更加低能耗建筑设计思想及实践体系, 为未来新农村建设 的低碳可持续化发展是一种良好的途径。（见图 6, 图 7)

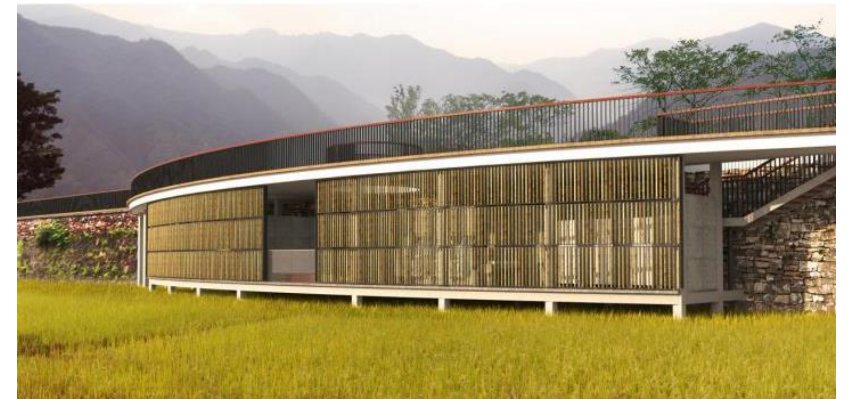

图 6 浙江临安市指南村公共则所设计方案一

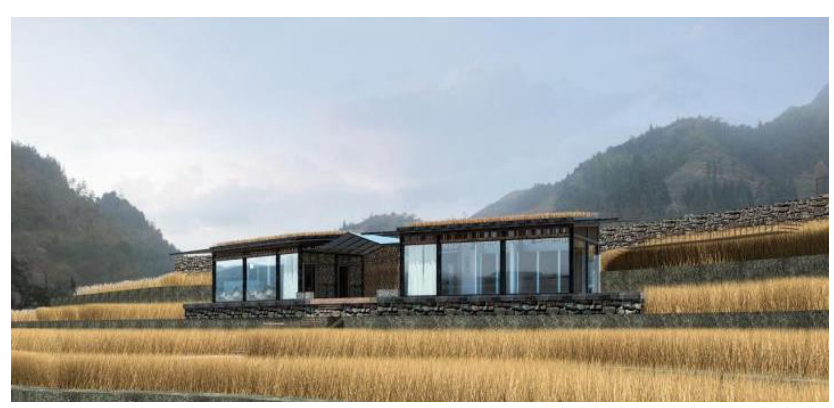

图 7 浙江临安市指南村公共则所设计方案二

\section{2. 竹建构在新农村建设中的技术问题}

在传统农村建筑中, 作为结构的竹常用绑扎和榫接的建构方式连接, 作为维护的墙体多 用竹筏的编织建构方式。 
绑扎是传统农村竹建筑中常用的连接方式, 在我国云南一些 少数民居中, 多用棕绳等对竹材进行绑扎, 到后来开始用铁丝增 强绑扎强度。古人在长期的建造过程中总结出了多种绑扎方法以 提高节点强度, 但由于竹材本身圆形的截面, 以及绑孔本身的柔 性连接特点, 使得绑扎节点容易松动, 不利于建筑的稳定性, 且 传统绑扎件的做法耐久性不高, 同样影响建筑的使用寿命。传统 建造技术下，竹构节点受材料自身特性限制较大，节点类型相对



图 8 传统竹构节点绑扎图示 单一。

随着技术的发展，金属配件和混泥土技术的应用，促使竹节点构造技术能够突破自身材 料特性的限制。现代竹构的做法是让竹材在节点处先将力传递给金属构件, 然后再传递给与 其连接的竹材，对于竹材而言，在节点处的受力是最为集中的，而竹材有着易开裂的缺点。 因此在节点处最容易开裂, 如何在节点处使用相对集中荷载能力较强的金属构件, 发挥竹材 较强的抗拉、抗压能力等优势是目前竹建构研究的主要难题。

\section{四、结论}

竹建构技术运用到新农村建设中，是一种回归。竹材在建筑中的运用自古已有，不论中 外, 竹材被很多村落居民选中作为营建家园的主要材料。在中国的西南部, 竹产量丰富, 当 地少数民族的传统民居就是竹楼; 在非洲, 竹产量并不多, 仍有部落居民用竹编的方法制造 能够遮蔽风雨的屋舍; 在盛产竹子的东南亚, 太平洋小岛上的许多乡土住屋都由竹子搭建而 成; 而竹产量颇丰的南美洲, 拥有大量竹建构设计师, 竹屋的建造数量在世界上首屈一指。 随着现代技术的发展, 以及人们对竹建构优良的力学性能和经济、生态的材料属性认知的不 断加深, 竹建构作为可持续发展的主要绿色建筑结构, 其运用于建筑的生态意义显著, 竹材 是一种极具环境和生态效益的建筑用材。在新农村建设中, 建筑师们不仅在乡土建造方面对 竹构建造有所发展, 在新建筑的设计建造中也积极引进、运用竹建构及适宜的技术, 表现竹 建构自然质朴的美学价值。在灾后重建和贫困地区的新农村人居环境营造工作中, 竹材的经 济性为快速建造廉价的房屋提供了良好的思路, 质朴的竹构建筑在建筑师的悉心构思下呈现 出深切的人文关怀。

竹建构的运用及其表现的形式和空间是表现新农村建设中建筑本质回归的良好途径。竹 建构体现的文化内涵和场所精神以及所揭示的建筑内涵, 是值得每一个新农村建设者借鉴和 反思的。

\section{致谢}

本文为武汉科技大学大学生科技创新基金项目（16ZRB158）的阶段性成果之一。

\section{References}

[1] Hunan University has built the world's first bamboo bridge that open to traffic, Hunan Daily , 2007.

[2] "Zhejiang Agricultural and Forestry University · International Bamboo and Rattan Organization of African Agriculture and Forestry Research Institute" was established., Journal of Zhejiang Agricultural and Forestry University, 2013.

[3] Wang Shu, Gao Jing, Ordinary Bamboo Works[D], China Academy of Art Master thesis , 2011.

[4] Tan Gangyi, Yang Liu, Construction of Bamboo[M], Nanjing: Southeast University Press , 2014. 